\title{
A aritmética do ajuste fiscal e o crescimento econômico no Brasil
}

\author{
Fernando Motta Correia*
}

RESUMO - A relação de causalidade entre programas de ajuste fiscal e crescimento econômico, na maioria das vezes torna a política fiscal uma importante fonte de contração da demanda agregada. Porém, dependendo do ajuste que se implementa, a relação inversa entre contração fiscal e crescimento econômico pode não se verificar, tornando a política fiscal uma fonte de crescimento econômico sem comprometer a sustentabilidade da dívida pública. Este artigo faz uma breve discussão entre o ajuste fiscal implementado no Brasil desde 1999 e possíveis fontes de crescimento econômico.

Palavras-chave: Ajuste fiscal. Crescimento econômico.

Desde 1999 a política fiscal brasileira tem o importante objetivo de gerenciar o chamado processo de ajuste fiscal, este nada mais é que a implementação de corte nos gastos públicos ou aumento de impostos tendo em vista a necessidade de geração de um esforço fiscal capaz de manter constante a relação dívida/PIB.

A definição do montante necessário que o setor público deve perseguir para manter a dívida sustentável exige uma diferença na análise dos principais indicadores fiscais. Por exemplo, o resultado nominal é o balanço entre as despesas totais e as receitas totais, e corresponde à necessidade de financiamento do setor público (NFSP). O resultado nominal equivale à variação total da dívida fiscal líquida no período pelo método abaixo da linha ${ }^{5}$. O resultado operacional corresponde ao resultado nominal, excluída a parcela referente à atualização monetária da dívida líquida. O resultado primário corresponde ao resultado nominal, excluída a parcela referente aos juros nominais sobre a dívida líquida.

O resultado primário, uma vez que não considera a apropriação de juros sobre a dívida existente, evidencia o esforço fiscal do setor público. Por meio desse conceito, é possível observar o empenho do setor público em equilibrar suas contas, desconsiderando o montante dos déficits incorridos no passado. Se o setor público gasta menos do que arrecada, se não é considerada a apropriação de juros sobre a dívida existente, há superávit primário.

\footnotetext{
* Doutorando do Programa de Pós Graduação em Desenvolvimento Econômico da UFPR. Endereço eletrônico: fmottabr@yahoo.com.br.

5 O método "acima da linha" apura o resultado fiscal pela diferença entre fluxos e o método "abaixo da linha" pela diferença entre estoques. Como vantagens, o primeiro conceito permite o melhor acompanhamento da execução orçamentária pelo controle das receitas e despesas, enquanto o segundo método assegura a homogeneidade das informações e permite a análise adequada do financiamento do setor público.
} 
Quando o setor público arrecada impostos, este será utilizado para consumo e para investimento. Por consumo entendem-se os gastos não-financeiros, como o pagamento de salário dos servidores públicos e a aquisição de bens e serviços (publicidade, aluguéis, remédios, etc.). Investimento do setor público são as despesas geradas na construção de estradas, hospitais, hidroelétricas e demais itens de infra-estrutura. O que excede, ou seja, a diferença entre o que arrecada e o que gasta, é a poupança do governo, o superávit primário. Este se destina ao pagamento dos juros, ou seja, os encargos da dívida pública.

$\mathrm{Na}$ administração das receitas e gastos públicos, podem-se identificar dois tipos de consolidação fiscal: o primeiro envolve um ajustamento que se baseia em cortes de gastos, sobretudo cortes nas despesas correntes ou gastos não financeiros; o segundo baseia-se principalmente no incremento de impostos e no corte de investimento público.

Em termos agregados, sem qualificar o tipo de consolidação fiscal que vem sendo implementado no Brasil, observa-se que o superávit primário não tem sido suficiente para pagar os juros, tendo o governo a necessidade de contrair novos empréstimos para rolar sua dívida e honrar os juros, o que aumenta ainda mais o estoque da dívida e compromete os orçamentos futuros. No ano passado, por exemplo, para pagar juros equivalentes a cerca de $6 \%$ do PIB, o governo fez superávit primário de 3,9\%. Teve, então, déficit nominal de $2,1 \%$ do PIB, como pode ser visto nos gráficos da página seguinte. Ou seja, teve de contrair novos empréstimos para pagar juros e o estoque da dívida do governo aumentou.

Um importante efeito para a economia brasileira quando do alcance da manutenção da estabilidade da relação dívida/PIB, ou mesmo quando esta relação passasse a ser decrescente seria a liberação de mais recursos para investimentos públicos e/ou redução da carga tributária. Além disso, não se podem questionar os efeitos gerados na manutenção do compromisso de se preservar uma trajetória sustentável para a dívida pública, uma vez que o resultado dos ganhos de credibilidade da política fiscal seria o fato dos agentes projetarem uma dívida menor para o futuro, o que por conseqüência geraria expectativas de um menor esforço fiscal no futuro, estando a dívida decrescendo ao longo do tempo.

Entretanto, parece que a aritmética do ajuste fiscal brasileiro está apontada por um caminho onde há uma relação inversa de causalidade entre o ajuste e crescimento econômico. Como o gasto público e o montante de tributos são importantes componentes da demanda agregada, programas de ajuste fiscal geram por conseqüência reduções no PIB e, portanto desestimulam o crescimento econômico. Ocorre que dependendo do tipo de política fiscal 
escolhida, o ajuste, em vez de estimular uma redução do produto, pode incentivar uma ampliação no crescimento econômico sem comprometer a credibilidade da política fiscal.

GRÁFICO 1 - NFSP NO BRASIL - JUROS NOMINAIS - 1985 - 2007

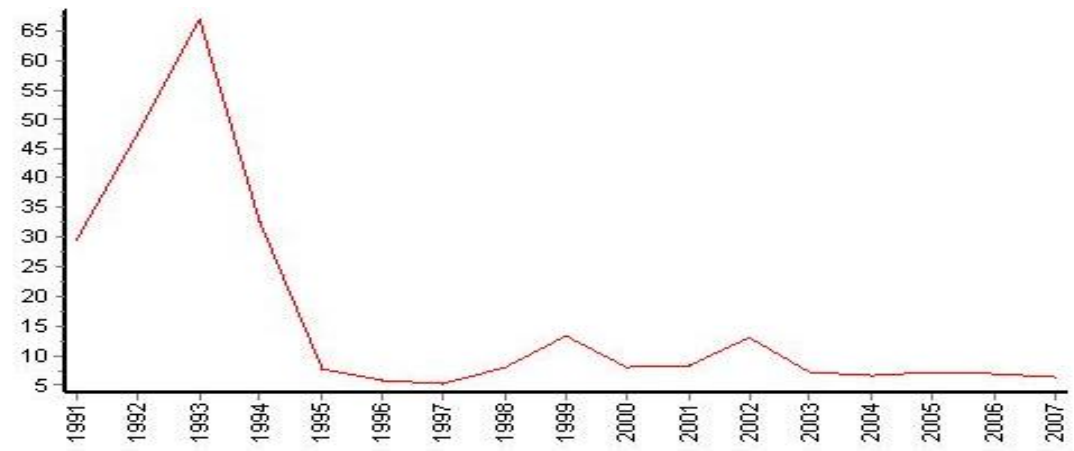

FONTE: IPEADATA (NFSP - setor público - juros nominais - c/ desvalorização cambial).

GRÁFICO 2 - SALDO PRIMÁRIO DO SETOR PÚBLICO NO BRASIL - 1985 - 2007

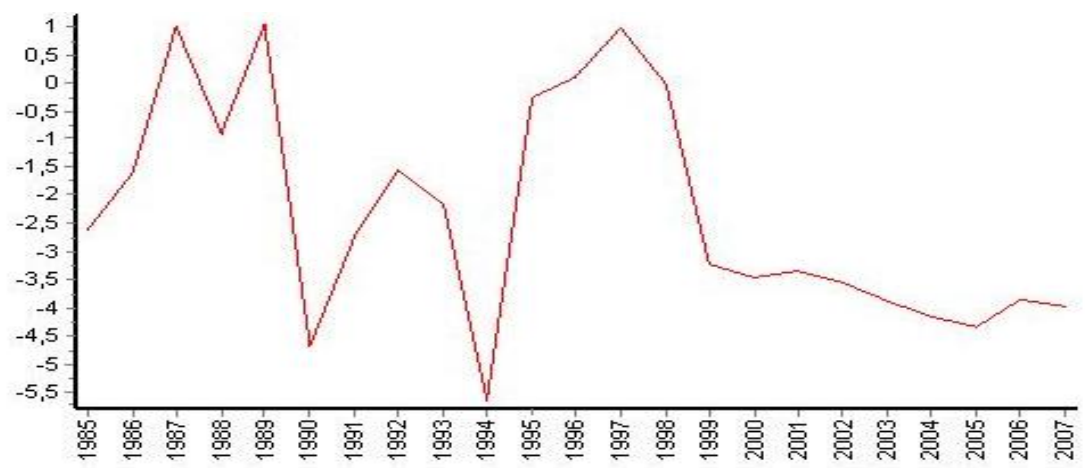

FONTE: IPEADATA (NFSP - setor público - primário - c/ desvalorização cambial).

GRÁFICO 3 - DÉFICIT NOMINAL DO SETOR PÚBLICO NO BRASIL - 1981 - 2007

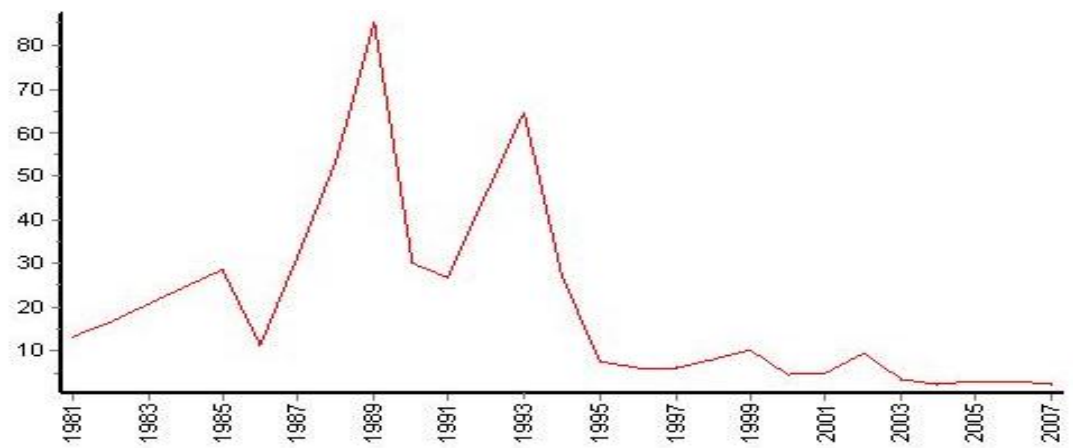

FONTE: IPEADATA (NFSP - setor público - nominal - c/ desvalorização cambial).

Se o governo sinaliza a implementação de um programa de ajuste fiscal por meio de cortes nas despesas correntes, equivale dizer que houve uma mudança no gerenciamento das contas públicas, ou seja, houve um ajuste sem o repasse de custos para o contribuinte. Se o ajuste é efetuado tendo por base um incremento nos impostos, os indivíduos não terão a certeza de que modo o incremento de receita será usada. Nesse segundo caso, a autoridade 
fiscal gera expectativas incertas quanto a trajetória das variáveis fiscais e por conseqüência incertezas quanto a possibilidade de se preservar uma dívida sustentável; estamos, portanto lidando com políticas do tipo discricionária.

O uso de políticas do tipo discricionárias pode contribuir para a adoção de medidas fiscais onde, em alguns momentos, haja uma redução do esforço fiscal, tornando o custo financeiro de manter a dívida pública estável um pouco menos sufocante. Neste cenário as expectativas de déficits futuros e o efeito dessas expectativas sobre os gastos públicos e tributos teriam importantes implicações no atendimento da restrição fiscal do governo, de modo que a autoridade fiscal age caso a caso escolhendo a política mais adequada num dado momento.

Se a conduta da política fiscal é do tipo discricionária, o governo deve ter a preocupação de não incorrer em problemas os quais os economistas chamam de "inconsistência temporal" da política econômica. Em alguns casos, embora haja a clara preocupação de manter um orçamento equilibrado, com a não utilização de políticas fiscais pró-cíclicas, os indivíduos tendem a desconfiar dos anúncios das medidas fiscais, o que compromete as expectativas quanto aos déficits futuros prejudicando todo o arcabouço da política econômica. É bem verdade que políticas fiscais pró-cíclicas sinalizam um descomprometimento quanto à manutenção de um orçamento equilibrado no lado dos gastos públicos. No entanto, em muitos casos a elevada demanda por recursos públicos inviabiliza a consecução de uma política fiscal anti-cíclica, o que compromete também a implantação de programas de ajuste fiscal devido o elevado esforço orçamentário exigido. Em alguns casos, um importante elemento do perfil de muitos governos justifica a inviabilidade na consecução de políticas fiscais anti-cíclicas, como o caso de governos populistas.

Até que ponto a política fiscal é considerada um instrumento que minimiza as instabilidades suscetíveis em qualquer economia diante dos anseios e demandas por investimentos sociais? Mais ainda, em que medida pode-se atribuir a origem de uma política pro-cíclica, seja por elevadas demandas sociais ou por características de governos populistas? Em países como o Brasil esses dois elementos se confundem, dando margem aos governos populistas a fazer gastos desenfreados tendo como justificativa o anseio social por maiores gastos em serviços públicos.

O que devemos apreender antes de tudo é que justificar o tipo de política fiscal, seja ela anti-cíclica ou pro-cíclica, exige um esforço analítico subjetivo, sobretudo porque uma das características fundamentais do atual estágio da modernidade é a legitimidade da democracia 
como mecanismo ordeiro político nas sociedades contemporâneas; como na democracia revezam-se agremiações partidárias de cunho ideológico adversos, a reposta que justifica a origem de qualquer política fiscal pode estar nas interpretações acerca das mudanças que acompanham o processo de transição política.

O mais importante aqui é perceber o teor discricionário envolvido no gerenciamento da política fiscal, sobretudo no lado dos gastos públicos, mas não isenta a necessidade de envolvimento da autoridade fiscal como cônjuge atuante para o sucesso de uma política de aumento no crescimento econômico. Projetar um ajuste fiscal pautado em incrementos nos impostos, além de gerar incertezas acerca do modo como as receitas serão utilizadas, acaba estimulando cortes nos gastos em investimentos, variável de suma importância na promoção do crescimento econômico, haja vista o vício que os governos populistas têm em ampliar os gastos correntes.

Assim, a perseguição de uma meta de superávit primário suficiente para pagar os juros e estabilizar relação dívida/PIB, embora seja necessária para garantir o crescimento sustentado, sem inflação e sem aumento da taxa de juros, poderia buscar um teor menos convencional de desestimulo ao crescimento econômico, se pautando em cortes em gastos correntes, não ampliando a carga tributária e reduzindo gastos em investimentos.

\section{REFERÊNCIAS}

Necessidade de financiamento do setor público (NFSP) - setor público - juros nominais - com desvalorização cambial. Ipeadata, 2008. Disponível em: $<<$ http://www.ipeadata.gov.br/ ipeaweb.dll/ipeadata?SessionID=1692991861\&Tick=1213895858912\&VAR_FUNCAO=Ser _Temas\%28127\%29\&Mod=M>>. Acesso em: 14/06/2008.

Necessidade de financiamento do setor público (NFSP) - setor público - conceito primário - com desvalorização cambial. Ipeadata, 2008. Disponível em: $<<$ http://www.ipeadata.gov.br

/ipeaweb.dll/ipeadata?SessionID=1692991861\&Tick=1213895858912\&VAR_FUNCAO=Se r_Temas\%28127\%29\&Mod=M >>. Acesso em: 14/06/2008.

Necessidade de financiamento do setor público (NFSP) - setor público - conceito nominal - com desvalorização cambial. Ipeadata, 2008. Disponível em: < http://www.ipeadata.gov.br/

ipeaweb.dll/ipeadata?SessionID=1692991861\&Tick=1213895858912\&VAR_FUNCAO=Ser _Temas $\% 28127 \% 29 \& M o d=M ~>>$. Acesso em: 14/06/2008. 
